ruột non bóng đơn Tap chí khoa học Tiêu hoá Việt Nam, IX(37), 2447 - 2454.

7. B. L. Zhang, C. X. Chen and Y. M. Li (2012) Capsule endoscopy examination identifies different leading causes of obscure gastrointestinal bleeding in patients of different ages. Turk J Gastroenterol, 23(3), 220-5.
8. C. N. Zhu, J. Friedland, B. Yan et al (2018). Presence of Melena in Obscure Gastrointestinal Bleeding Predicts Bleeding in the Proximal Small Intestine. Dig Dis Sci, 63(5), 1280-1285.

9. Z. Wang, J. Q. Chen, J. L. Liu et al (2013). CT enterography in obscure gastrointestinal bleeding: a systematic review and meta-analysis. J Med Imaging Radiat Oncol, 57(3), 263-73.

\title{
NGHIÊN CỨU ÁP DỤNG CHỌC HÚT BẰNG KIM NHỎ DƯớI HƯớNG DẪN SIÊU ÂM TRONG CHẨN ĐOÁN MộT Số TỔN THƯƠNG KHU TRÚ Ở TỰ
}

\author{
Nguyễn Thu Lan*, Nguyễn Thái Bình**, Nguyễn Ngọc Cương **, \\ Đào Thị Luận**, Bùi Văn Lệnh**
}

\section{TÓM TẮT}

Việc xác định đúng bản chất giải phẫu bệnh của tổn thương khu trú của tụy là vố cùng quan trọng, quyết đinh thái đô điều tri. Có nhiêu phương pháp để lấy bệnh phẩm tụy như chọc hút kim nhỏ dưới hướng dần của siêu âm $(S A)$, siêu âm nôi soi (SANS), sinh thiết tụy trong phẩu thuật, sinh thiết tụy dưới hướng dẫn SÄ, cắt lớp vi tính (CLVT). Chúng tôi nghiên cứu 18 bệnh nhân $(\mathrm{BN})$ có tổn thương khu trú ở tụy và được choc hút tế bào bằng kim nhỏ dưới hướng dẫn siêu âm. Kết quả: số lân chọc hút trung bình 1,4 lần/BN. 17/18 bệnh nhân không đau trong quá trình làm thủ thuật. Độ nhạy, độ đặc hiệu, giá trị dự báo dương tính, giá trị dự báo âm tính, độ chẩn đoán chính xác của phương pháp chọc hút tế bào bằng kim nhỏ dưới siêu âm trong chẩn đoán ung thư tụy lần lượt là $90,9 \%, 100 \%, 100 \%, 87,5 \%$ và $94,4 \%$. $100 \%$ không có biên chứng sau thủ thuật. Kết luận: Chọc hút tế bào bằng kim nhỏ dưới hướng dấn siều âm là phương phá an toàn, hiệu quả cao để chẩn đoán tổn thương khu trú ở tụy, đặc biête là ung thư tụy.

Từ khóa: tổn thương khu trú của tụy, chọc hút kim nhỏ, siêu âm, ung thư tụy.

\section{SUMMARY}

\section{VALUE OF ULTRASOUND-GUIDED FINE NEEDLE ASPIRATION IN DIAGNOSIS OF FOCAL PANCREATIC LESIONS}

Confirmation of the nature of focal pancreatic lesions plays a pivotal role in treatment. There are many different types of sampling procedures such as ultrasound-guided fine needle aspiration (US FNA), endoscopic ultrasound-guided fine needle aspiration (EUS FNA), surgical biopsy, ultrasound guided biopsy and computed tomography. We reviewed 18 consecutive ultrasound-guided fine-needle aspiration

\footnotetext{
*Trường Đai hoc Y Hà Nôi

**Bênh viền Đai hoc Y Hà Nôi

Chịu trách nhiệm chính: Nguyễn Thu Lan

Email: nguyenthulan16051995@gmail.com

Ngày nhận bài: 5.7.2021

Ngày phản biên khoa hoc: 30.8.2021

Ngày duyệt bài: 7.9.2021
}

cytological sampling procedures for focal pancreatic lesions. Result: median number of aspiration was 1.4 times/patient, painless was seen in 17/18 patients. Sensitivity, specificity, positive prediction value and negative prediction value of US FNA in diagnosis pancreatic cancer were $90.9 \%, 100 \%, 100 \%, 87.5 \%$ and $94.4 \%$, respectively. No complications related to US-FNA were noted. Conclusion: US FNA cytological sampling is safe and effective for the diagnosis and planning of management of focal pancreatic lesions, especially pancreatic cancer.

Key words: focal pancreatic lesions, US FNA, pancreatic cancer.

\section{I. ĐẶT VẤN ĐỀ}

Tổn thương khu trú của tụy ngày càng gia tăng do được phát hiện môt cách ngẫu nhiên ${ }^{1}$. Dựa trên bản chất giải phẩu bệnh, tổn thương khu trú của tụy được chia thành tổn thương lành tính, tổn thương tiền ung thư và ung thư. Việc xác định đúng bản chất giải phẫu bệnh của tổn thương là vô cùng quan trọng, quyết định đến thái độ điều trị tiếp theo. Chẩn đoán phân biệt các tổn thương khu trú của tụy có thể dựa vào lâm sàng, các phương pháp chẩn đoán hình ảnh như $S A, C L V T, C H T$, SANS và các xét nghiệm hóa sinh nhưng các phương pháp này chỉ gợi ý tính chất lành tính/ ác tính của tổn thương, không thể thay thế được giải phẫu bệnh. Chẩn đoán tễ bào học và mô bênh học giúp chúng ta biết bản chất khối khu trú ở tụy, giúp khẳng định chẩn đoán và có kế hoạch điều trị thích hợp. Có nhiều phương pháp để lấy bệnh phẩm tụy như chọc hút kim nhỏ dưới hướng dẫn của SA, SANS, sinh thiết tụy trong phẫu thuật, sinh thiết tụy dưới hướng dẫn SA,CLVT. Trong đó, chọc hút kim nhỏ tổn thương tụy dưới hướng dẫn siêu âm có các ưu điểm: kết quả chính xác cao, an toàn, chi phí thấp, không nhiễm xạ. Vì thế chọc hút kim nhỏ dưới hướng dẫn SA được xem là một kỹ thuât được ưu tiên lựa chọn trong chẩn đoán tổn 
thương khu trú của tụy. Nghiên cứu của chúng tôi nhằm đánh giá đặc điểm hình ảnh một số tổn thương khu trú của tụy và tính an toàn, giá trị chẩn đoán của chọc hút bằng kim nhỏ dưới hướng dẫn SA trong chẩn đoán các tổn thương này.

\section{II. ĐỐI TƯợNG VÀ PHƯƠNG PHÁP NGHIÊN CỨU}

Đối tượng nghiên cứu: Gồm 18 BN có tổn thương khu trú ở tụy, được chọc hút tế bào bằng kim nhỏ dưới hướng dẫn của siêu âm tại Bệnh viện Đại học $Y$ Hà Nội từ tháng 2/2020 đến tháng 9/2021 và có đầy đủ thông tin nghiên cứu. ngang

Phương pháp nghiên cứu: Mô tả cắt

\section{Quy trình nghiên cứu:}

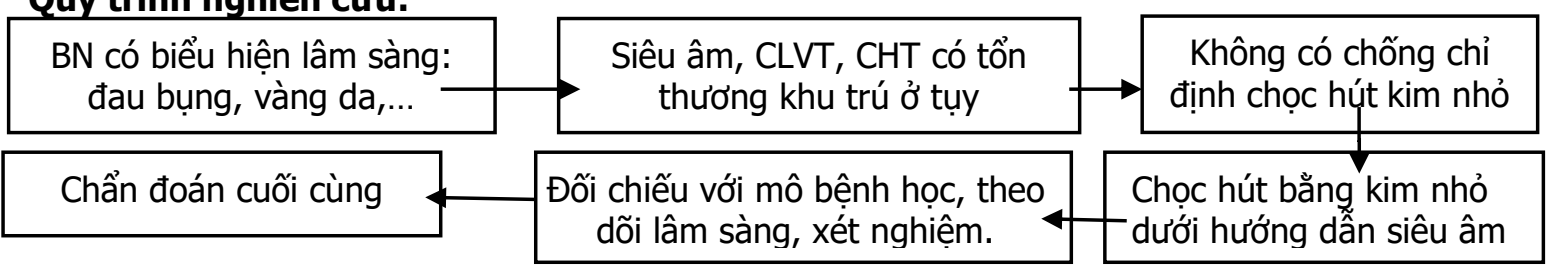

\section{KẾT QUẢ NGHIÊN CỨU VÀ BÀN LUẬN}

Trong 2 năm, chúng tôi đã tiến hành nghiên cứu 18 trường hợp chọc hút tế bào bằng kim nhỏ một số tổn thương khu trú của tụy dưới hướng dẫn của siêu âm với độ tuổi trung bình chung là $57,61 \pm 11,57 \%$, của nhóm ung thư tụy là $60 \pm 10,92$, của nhóm viêm tụy giả u là $57,61 \pm 12,4$. Tỉ lệ nam: nữ là $2: 1$. Kích thước trung bình của các tổn thương của tụy trên siêu

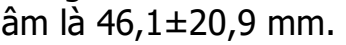

Kết quả chọc hút tế bào bằng kim nhỏ dưới hướng dẫn siêu âm

Về kĩ thuật: 18BN (100\%) đều sử dụng kim chọc hút Chiba 21G. Trong các nghiên cứu khác, các tác giả sử dụng nhiều cõ kim chọc hút từ 20G đến 23G2,3. Cõ̃ kim này giúp lấy đủ bệnh phẩm cần thiết cũng như giảm nguy cơ biến chứng.

Vị trí chọc hút nhiều nhất là đầu tụy chiếm $66,7 \%$, vị trí thân và đuôi tụy với tỷ lệ lần lượt là $22,2 \%$ và $11,1 \%$.

Bảng 1 Kêt quả chọc hút tế bào theo số lân chọc hút

\begin{tabular}{|c|c|c|c|c|}
\hline & & \multicolumn{2}{|c|}{$\begin{array}{c}\text { Kết quả chọc hút } \\
\text { tế bào }\end{array}$} & \multirow[b]{2}{*}{ p } \\
\hline & & $\begin{array}{l}\text { Ung thu' } \\
(\mathrm{n}=10)\end{array}$ & $\begin{array}{l}\text { Không ung } \\
\text { thư }(n=8)\end{array}$ & \\
\hline \multirow{2}{*}{$\begin{array}{c}\text { Số lần } \\
\text { chớc } \\
\text { hứt }\end{array}$} & \begin{tabular}{|c|}
$\begin{array}{c}\text { Chọc } 1 \text { lân } \\
(\mathrm{n}, \%)\end{array}$ \\
\end{tabular} & $\begin{array}{c}3 \\
(30 \%) \\
\end{array}$ & $\begin{array}{c}7 \\
(70 \%) \\
\end{array}$ & \multirow{3}{*}{0,025} \\
\hline & $\begin{array}{c}\text { Chọc } 2 \text { lần } \\
(\mathrm{n}, \%)\end{array}$ & $\begin{array}{c}7 \\
(87,5 \%)\end{array}$ & $\begin{array}{c}1 \\
(12,5 \%)\end{array}$ & \\
\hline & ông số & 10 & 8 & \\
\hline
\end{tabular}

Chú thích: Chọc hút 2 lần có nghĩa là qua kiểm tra sơ bộ bằng mắt thường trến phiến đồ 1 , chúng tôi thây khả năng không đủ tế bào học để chẩn đoán nên chọc hút tiếp lần 2 ngay sau chọc lần 1.

Số lần chọc hút là 26 lần/18 bệnh nhân. Số lần chọc hút trung bình 1,4 lần/BN, cao hơn so với nghiên cứu của Giulia A.Zamboni là trung bình 1,2 lần/BN. Theo nghiên cứu của chúng tôi, chọc hút tế bào tụy bằng kim nhỏ dưới hướng dẫn siêu âm 2 lần cho kết quả ung thư cao hơn 1 lần có ý nghĩa thống kê với $\mathrm{p}<0,05$. Như vậy số lần chọc kim ảnh hưởng đến kết quả tế bào học. Một số tác giả cho rằng 2 hoặc 3 lần chọc kim qua tổn thương giúp đảm bảo bệnh phẩm ${ }^{3,4}$. $100 \%$ trường hợp chọc hút tế bào đủ bệnh phẩm đọc tế bào học, tỷ lệ này cao hơn so với nghiên cứu của Giulia A.Zamboni là trung bình $84.6 \%$.

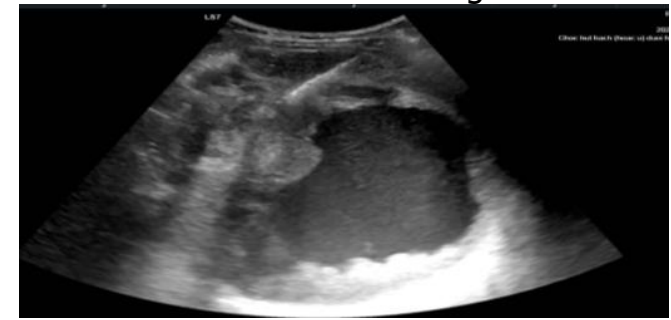

Hình 1: Hình ảnh siêu âm: kim chọc hút nằm trong khôi u tụy.

Trong quá trình chọc hút, đa số các bệnh nhân không đau chiếm tỷ lệ $94,4 \%$, chỉ có $1 / 18$ bệnh nhân đau và đau ở mức độ nhe với VAS bằng 2 điểm. Trong các nghiên cứu khác, tỉ lệ đau bụng sau chọc hút cũng thường ít xảy ra. Theo nghiên cứu của Jae Bock Chung ${ }^{3}$, đau xảy ra ở 1/39 BN tương đương tỉ lệ $2.6 \%$, trong khi nghiên cứu của Giulia A.Zamboni Giulia ${ }^{4}$, đau xảy ra với 6/545 BN. Với việc gây tê tốt vị trí ngay dưới bề mặt da và phúc mạc thành bụng, $B N$ hầu như không đau.

\section{Về kết quả tế bào học:}

Bảng 2. Kêt quả chọc hút tế bào bằng kim nhỏ dưới hướng dẫn siêu âm trong chẩn đoán một số tổn thương khu trú ở tụy

\begin{tabular}{|c|c|c|}
\hline $\begin{array}{l}\text { Chôc hút } \\
\text { tế bào }\end{array}$ & $\begin{array}{c}\text { Nhẩn đoán Chấn đoán đước } \\
\text { cuối cùng }\end{array}$ & $\begin{array}{c}\text { Chắng chooc hút } \\
\text { tế bào }\end{array}$ \\
\hline Ung thư tụy & $11(61,1 \%)$ & $10(55,6 \%)$ \\
\hline
\end{tabular}




\begin{tabular}{|c|c|c|}
\hline Viêm & $7(38,9 \%)$ & $2(11,1 \%)$ \\
\hline Không điến hình & $0(0 \%)$ & $6(33,3 \%)$ \\
\hline Tống & $\mathbf{1 8}$ & $\mathbf{1 8 ( 1 0 0 \% )}$ \\
\hline
\end{tabular}

18 bệnh nhân tham gia nghiên cứu của chúng tôi được chia thành hai nhóm với chẩn đoán xác đinh cuối cùng là ung thư tụy (11 bệnh nhân) và viêm tụy giả u ( 7 bệnh nhân).

18 bệnh nhân này đều được tiến hành chọc hút tế bào bằng kim nhỏ dưới hướng dẫn siểu âm, kết quả tế bào học của $10(55,6 \%)$ bệnh nhân là ung thư tụy, $2(11,1 \%)$ bệnh nhân là viêm tụy, $6(33,6 \%)$ bệnh nhân tế bào học không điển hình.

Bảng 3. Giá trị chọc hút bằng kim nhỏ dưới hướng dẫn siêu âm trong chẩn đoán ung thư tuy

\begin{tabular}{|c|c|c|c|c|}
\hline Nhóm & Ung thu & Không & & \\
\hline $\begin{array}{l}\text { Choc hút } \\
\text { tế bào }\end{array}$ & tụy & $\begin{array}{c}\text { ung thu } \\
\text { tụy }\end{array}$ & Tống & $\mathbf{P}$ \\
\hline Ung thư tụy & 10 & 0 & 10 & \\
\hline Không ung thu & 1 & 7 & 8 & 0,0 \\
\hline Tống & 11 & 7 & 18 & \\
\hline
\end{tabular}

Trong nghiên cứu của chúng tôi, độ nhạy, độ đặc hiệu, giá trị dự báo dương tính, giá trị dự báo âm tính, độ chẩn đoán chính xác của phương pháp chọc hút tế bào bằng kim nhỏ dưới siêu âm trong chẩn đoán ung thư tụy lần lượt là $90,9 \%, 100 \%, 100 \%, 87,5 \%$ và $94,4 \%$. Kết quả này tương tự kết quả nghiên cứu của Hassan Okasha và cộng sự với độ nhạy $85,5 \%$, độ đặc hiệu $90,4 \%$, giá trị dự báo dương tính 94,7\%, giá trị dự báo âm tính 76\%, độ chẩn đoán chính xác $88,9 \%$. Độ đặc hiệu và giá trị dự báo dương tính rất cao. Điêu này cho thây: Nếu chọc hút kim nhỏ dưới hướng dẫn siêu âm là ung thư thì khả năng là ung thư tụy rất cao (trong nghiên cứu này không thấy dương tính giả).

Về biến chứng: Các biến chứng có thể gặp gồm đau bụng, tụ máu thành bụng, nhiểm khuẩn, xuất huyết tiêu hóa, thủng tạng rỗng, viêm tụy cấp, di căn theo đường phúc mạc,... Trong nghiên cứu của chúng tôi không có trường hợp nào có biến chứng sau chọc hút tế bào bằng kim nhỏ. Theo nghiên cứu Mirko $D^{\prime}$ Onofrio và cộng sự, tỉ lệ biến chứng khoảng $0.8 \%$, trong khi cá nghiên cứu khác cho thấy tỉ lệ này dao động khoảng $0 \%$ tới $5 \% \%^{3,6,7}$. Theo Prateek Bhatia và cộng sự, nghiên cứu trên 267 bệnh nhân cho thấy ngoại trừ cơn đau nhẹ, không có bệnh nhân nào gặ̆p biến chứng nghiêm trọng như thủng tạng rổng, viêm phúc mạc, viêm tụy cấp sau thủ thuật ${ }^{8}$.

\section{KẾT LUÂN}

Các phương pháp chẩn đoán hình ảnh như siêu âm, cắt lớp vi tính và cộng hưởng từ là phương pháp quan trọng trong đánh giá khối của tụy, góp phần gợi ý chẩn đoán phân biệt ung thư tụy và viêm tụy giả u, tuy nhiên không đặc hiệu và không chẩn đoán được giải phẫu bểnh. Chọc hút tế bào bằng kim nhỏ dưới hướng dẫn của siêu âm là phương pháp có độ nhạy, độ đặc hiệu cao, cũng như ít xâm lấn và an toàn để chẩn đoán giải phẫu bệnh của các tổn thương khu trú của tụy, đặc biệt trong trường hợp ung thư tụy.

\section{TÀI LIẸU THAM KHẢO}

1. Best LM, Rawji V, Pereira SP, Davidson BR, Gurusamy KS. Imaging modalities for characterising focal pancreatic lesions. Cochrane Database Syst Rev. 2017;4:CD010213. doi:10.1002/14651858.CD010213.pub2

2. Zamboni GA, $D^{\prime} O$ nofrio $M$, Idili $A$, et al. Ultrasound-Guided Percutaneous Fine-Needle Aspiration of 545 Focal Pancreatic Lesions. Am J Roentgenol. Published online November 23, 2012. doi:10.2214/AJR.09.2958

3. Chung JB, Chung DK, Kim DY, et al. Percutaneous Fine Needle Aspiration Biopsy of Pancreatic Cancer Guided by Ultrasonography. Korean J Intern Med. 1989;4(2):125-129. doi:10.3904/kjim.1989.4.2.125

4. Zamboni GA, D'Onofrio $M$, Idili A, et al. Ultrasound-Guided Percutaneous Fine-Needle Aspiration of 545 Focal Pancreatic Lesions. Am J Roentgenol. 2009;193(6):1691-1695. doi:10.2214/ AJR.09.2958

5. Okasha HH, Naga MI, Esmat S, et al. Endoscopic Ultrasound-Guided Fine' Needle Aspiration versus Percutaneous Ultrasound-Guided Fine Needle Aspiration in Diagnosis of Focal Pancreatic Masses. Endosc Ultrasound. 2013; 2(4):190-193. doi:10.4103/2303-9027.121239

6. D'Onofrio $M$, De Robertis $R$, Barbi $E$, et al. Ultrasound-guided percutaneous fine-needle aspiration of solid pancreatic neoplasms: 10 -year experience with more than 2,000 cases and a review of the literature. Eur Radiol. 2016;26(6):1801-1807. doi:10.1007/s00330-0154003-x

7. Matsubara J, Okusaka T, Morizane C, Ikeda M, Ueno $\mathbf{H}$. Ultrasound-guided percutaneous pancreatic tumor biopsy in pancreatic cancer: a comparison with metastatic liver tumor biopsy, including sensitivity, specificity, and complications. ] Gastroenterol. 2008;43(3):225-232. doi:10.1007/ s00535-007-2142-9

8. Ultrasound-guided percutaneous procedures in pancreatic diseases: new techniques and applications. Accessed September 9, 2021. https://www.ncbi.nlm.nih.gov/pmc/articles/PMC63 42746/ 